\title{
Tongan secondary students' conceptions of schooling in New Zealand relative to their academic achievement
}

\author{
Mo'ale 'Otunuku • Gavin T. L. Brown • Airini
}

Received: 30 August 2012/Revised: 14 April 2013/Accepted: 25 May 2013/Published online: 4 June 2013

(C) The Author(s) 2013. This article is published with open access at Springerlink.com

\begin{abstract}
This study examines the relationship between Tongan students' attitudes and beliefs towards their school experiences and their academic achievement on the highstakes National Certificate of Educational Achievement (NCEA) assessments in English and mathematics. Data were obtained from using previously published selfreported inventories on a sample of Tongan senior students in New Zealand secondary schools. Confirmatory factor analysis of students' conceptions found good fit measurement models for each domain (teaching, learning, and assessment). Structural equation modelling was used to identify the effect of the various beliefs upon students' total score in each subject and upon internal and externally assessed performance. It was noted that different beliefs became statistically significant predictors of performance, depending on the subject and type of assessment. Nonetheless, all three constructs played some role in at least one subject. A small-to-moderate proportion of variance in NCEA performance could be attributed to student beliefs, suggesting that efforts to help students adopt adaptive beliefs will have beneficial consequences for those students.
\end{abstract}

Keywords New Zealand - Tongan · Attitudes · Beliefs · Achievement

M. 'Otunuku ( $\square)$

University of the South Pacific, Nuku'alofa, Tonga

e-mail: moale.otunuku@usp.ac.fj

G. T. L. Brown · Airini

The University of Auckland, Auckland, New Zealand

e-mail: gt.brown@auckland.ac.nz

Airini

e-mail: airini@auckland.ac.nz
The academic performance of Tongan New Zealand students is a matter of real concern. Along with other students of Pacific Islands ethnicity, performance on national secondary school qualification assessments (i.e., National Certificate of Educational Achievement-NCEA) is much lower than other ethnic groups (MOE 2008) (e.g., in 2008, $9 \%$ fewer Pasifika ${ }^{1}$ students left school with at least NCEA Level 1 than European/Pakeha ${ }^{2}$ students; $13 \%$ fewer left with at least NCEA Level 2; and $25 \%$ fewer achieved University Entrance). This pattern has been observed from Grade 4 (age 10) onwards in reading, writing, and mathematics evaluated with international (i.e., TIMSS, PIRLS, PISA) and New Zealand core assessment tools and qualifications (i.e., as TTle, ${ }^{3}$ National Education Monitoring Project [NEMP], ${ }^{4}$ NCEA) measures of learning (Satherley 2006). While Tongan New Zealanders ('Tongan'), like other Pasifika groups, generally occupy the lowest levels of the socio-economic status (SES), such socio-economic factors are very difficult to change. In contrast, psychological beliefs, values, and attitudes are more amenable to change and also contribute to low academic performance. Thus, research into such psychological

\footnotetext{
1 'Pasifika' refers to the peoples with Pacific nation ethnicity living in New Zealand. The grouping is heterogenous and inclusive of peoples from diverse cultural, linguistic, and identity backgrounds. More than $60 \%$ of Pasifika New Zealanders were born in New Zealand.

${ }^{2}$ Is a Maori language word for New Zealanders who are of 'European descent'.

${ }^{3}$ An assessment tool, developed to assess students' achievement and progress in reading, mathematics, writing, and in panui, pangarau, and tuhituhi. The tool has been developed primarily for the assessment of students in year 5-10, but because it tests curriculum levels $2-6$, it can be used for students in lower and higher year levels.

4 A project that ran from 1995 to 2010 as a national study of students' outcomes.
} 
processes may generate useful insights for redressing poor achievement.

For example, Jones (1991) found that the beliefs concerning learning and teaching of Pasifika girls in a New Zealand high school were very different to those of their more academically successful Pakeha peers. Pasifika girls tended to treat learning as a matter of memorising and recalling what the teacher said and that this could be done effectively after school, and so classroom time could be used for inter-personal socialising. In contrast, the Pakeha girls treated learning as an interactive discussion with the teacher in which their opinions mattered, and so classroom time was used for a deepened understanding of curriculum material. These contrasting beliefs were, respectively, associated with low and high levels of academic performance. 'Otunuku and Brown (2007) reported that the correlation between students' self-reported efficacy and interest in reading, writing, and mathematics was positively correlated with achievement for Pakeha students and zerocorrelated for Pasifika students, including Tongan. They argued that not having a realistic and accurate sense of their own competence within each subject meant that Pasifika students would be less likely to implement appropriate study and learning behaviours.

While not drawing on the same theoretical perspective, results like these can be explained by psychological theories that focus on the role of beliefs, attitudes, and values on human intentions and behaviours. For example, Ajzen's theory of reasoned behaviour $(1991,2005)$ has shown that attitudes a person has, their sense of control or agency, and their awareness of social norms all influence intentions to behave in a certain way. Within the general idea of selfregulation, the beliefs a person has about their competence to learn and their control over their learning have also been shown to explain achievement (Schunk and Zimmerman 2006). In other words, some beliefs, values, or attitudes are more adaptive (i.e., associated with better learning outcomes) and others are maladaptive (i.e., associated with lower achievement).

While studies worldwide have demonstrated strongly how students' attitudes and beliefs appear to influence achievement (e.g., Akey 2006; Randel et al. 2000; Sarwar 2004; Stevenson et al. 1993; Udoukpong et al. 2012), these studies have limited direct applicability to this study's setting of Pacific Island Tongan students in New Zealand. Among the fewer studies with New Zealand students, it has been found that student beliefs about assessment, learning, and teaching have a statistically significant relationship with academic achievement. High school student beliefs about the nature and purpose of assessment (a form of control belief within self-regulation theory) explained sizeable proportions of variance in achievement on tests of reading or mathematics (ranging from 13 to $15 \%$ ) (Brown and Hirschfeld 2008; Brown et al. 2009b; Walton 2009). Further, Brown et al. (2009b) found, based on responses to the Student Conceptions of Assessment inventory, that the more students endorsed an external focus for assessment (i.e., assessment predicts personal futures or evaluates school) led to lower academic performance $(\beta=-0.82)$, while believing that assessment helped both teacher and students to improve led to higher performance $(\beta=0.65)$. Likewise, competence and control beliefs about the purpose of learning and learning approaches are statistically significant predictors of variation in PISA mathematics and reading achievement (Marsh et al. 2006). Among 15-year olds in the OECD PISA study, including New Zealand high school students, relationships of these factors to academic achievement were generally weak (i.e., $\beta<0.10$ ), except for control strategies ( $\beta=0.22$ in reading), academic selfconcept ( $\beta=0.22$ in reading, $\beta=0.15$ in mathematics), self-efficacy $(\beta=0.18$ in reading, $\beta=0.12$ in mathematics), and control expectation $(\beta=0.19$ in reading, $\beta=0.10$ in mathematics).Among New Zealand high school students, it was found that academic achievement on standardised tests of reading (15.9\% variance explained) and mathematics (11.4\% variance explained) was positively predicted by student endorsement of the idea that learning is a continuous process $(\beta=0.59)$ and negatively predicted by endorsement that learning is a duty $(\beta=$ -0.55) (Peterson et al. 2010). In New Zealand high schools, the Te Kotahitanga research into improving Maori student academic achievement (Bishop and Berryman 2006) has shown that student beliefs about their teachers (e.g., my teacher is racist against Maori people) interfered with student-teacher relationships as well as academic performance. When teachers were helped to change the quality of relationships, Maori student academic performance improved. Furthermore, a survey of over 600 Year 11 and 12 New Zealand students found stronger endorsement that teachers provided challenging teaching led to increased performance on a standardised reading test ( $\beta=0.29$ ) (Brown and Yu 2010).

While these studies do not establish causal relations per se, they show that there are consistently strong associations between self-reported beliefs and academic performance. In accordance with Ajzen's framework, such evidence is considered support for the contention that individuals' beliefs have a causal relationship to achievement outcomes, notwithstanding the reciprocal relationship of achievement upon belief structures which cannot be evaluated in cross-sectional studies. While the effect of psychological values, attitudes, and beliefs on academic achievement may not be as large as socio-economic factors, they are of interest because they are associated with differential outcomes and seem amenable to change. Hence, this study examines how the beliefs, attitudes, and 
opinions of Tongan high school students in New Zealand about teaching, learning, and assessment relate to their academic performance on the high-stakes national qualifications system. If reasons and beliefs predict behaviour, then this may help us identify beliefs which, if developed by Tongan students, would contribute to practices that reduce underachievement.

This study is important because no previous study of student beliefs has specifically focused on Tongan New Zealand students. Previous New Zealand studies have linked student beliefs about assessment (Brown and Hirschfeld 2008; Brown et al. 2009b), teaching (Brown and Yu 2010), and learning (Peterson et al. 2010) to performance on low-stakes or non-qualification assessments rather than a high-stakes qualification system. Furthermore, those same studies only used one-off test or examinationlike assessments as the measure of academic achievement, whereas the NCEA system uses a mixture of external examinations and internally assessed coursework. With a view to greater understanding of how psychological factors may influence low achievement at high school level, this study addresses the following research questions:

1. How do Tongan high school students conceive of the purposes of assessment, report their learning approaches, and evaluate their teaching?

2. What is the relationship of these competence and control beliefs to each other?

3. What is the relationship of the beliefs to academic performance in NCEA Level 1 English and Mathematics, taking into account differences between internal and externally awarded credits?

\section{The study}

A survey study of Tongan high school students was conducted to examine, using self-reported questionnaire batteries, student attitudes to teaching, learning, and assessment. Causal-correlational analysis of data was used to establish the structure of student beliefs (specifically confirmatory factor analysis [CFA]) and the relationship of beliefs to performance on the NCEA (specifically structural equation modelling [SEM]). While SEM normally requires large samples $(N>400)$ to ensure solutions are proper (Boomsma and Hoogland 2001), it is possible to use the technique with small samples by increasing the number of items per factors, ensuring all items had strong loadings on their factors $(>0.60)$, and combining factor indicators into item parcels (Marsh and Hau 1999).Marsh and Hau (1999) found that with 6 items per factor a sample size of $N=50$ were sufficient to generate acceptable solutions.
The study was conducted in Auckland where $80 \%$ of Tongan New Zealanders live (Statistics New Zealand 2007). Schools identified from the Education Review Office (ERO) webpage (www.ero.govt.nz/) to have a substantial number of Tongan students were approached for permission to survey students. Seven out of eleven schools (response rate $=64 \%$ ) agreed to allow student recruitment for the survey to take place.

The issue of low return rate was considered, and it was decided that the best way to increase the return rate was to allow students to complete the surveys at school and for the questionnaires to be collected before the students left the survey venues. Attending the survey was voluntary, and students were free to withdraw at any time. However, in most participating schools, most of the Tongan students (Year 12 \& 13) participated. All participating schools were able to provide both time during their school programmes and a room for the survey to be conducted. Those students who turned up at the allocated time and rooms agreed to participate, and the researcher was there to collect the completed surveys.

\section{Participants}

The participants were Year 12 and 13 Tongan students (nominally 17- and 18-year old respectively) who were enroled in 2008 in secondary schools in the Auckland region. Informed consents were obtained from the students to participate and their schools to release students' NCEA results. Schools in New Zealand are classified, according to the SES of the parents of enroled students, into one of ten categories or deciles (decile $1=10 \%$ of schools with the highest proportion of students from low socio-economic communities; decile $10=10 \%$ of schools with the lowest proportion of these students). Four participating schools were decile 1 , and the three remaining were, respectively, decile 2, 4, and 9 .

All participants who had answered less than $90 \%$ of the survey items were dropped from the analysis. With the balance, data missing at random was computed using the SPSS EM missing values procedure (Little and Rubin 2002). As a result, 189 students were available for analysis. Most participants ( $81 \%$ ) were in decile 1 or 2 schools, $10 \%$ in decile 4 , and only $6 \%$ were in the decile 9 school. The participants (Table 1) were mostly female (63\%), most were born in New Zealand $(65 \%)$ and most $(85 \%)$ attended church regularly with $62 \%$ going to Tongan language churches. Almost equal numbers of participants were enroled in Year 12 and 13, the final 2 years of New Zealand secondary schooling. All students had sat in the calendar year 2007 either for NCEA Level 1 or 2. NCEA internal assessments take place throughout the year, while examinations take place in November, and results for both internal and external assessments are released in January of the following year. 
Table 1 Participants' Characteristics

\begin{tabular}{lrl}
\hline Characteristics & Frequency & $\%$ \\
\hline Gender & 69 & \\
Male & 120 & 36.5 \\
Female & & 63.5 \\
School year & 96 & 50.8 \\
Year 12 & 93 & 49.2 \\
Year 13 & & \\
Country of birth & 123 & 65.0 \\
New Zealand & 59 & 31.0 \\
Tonga & & \\
Attending church & 161 & 85.2 \\
Yes & 28 & 14.8 \\
No & & \\
Tongan language church & 118 & 62.4 \\
Tongan & 50 & 26.5 \\
English & &
\end{tabular}

\section{Instruments}

The self-administered questionnaire used in this study explored students' attitudes to assessment, teaching, and learning, using previously published inventories.

The first inventory was the Students' Conceptions of Assessment (SCoA) by Brown (2006) which has 33 items aggregated into a hierarchical model of 7 first-order factors, distributed across three second-order inter-correlated factors: Improvement (teacher improves student, self-improvement), Beneficial (personal enjoyment, class enjoyment), External (school accountability, student future), and Irrelevant (firstorder factor). The Cronbach alpha estimate of reliability for the four factors was good: Improvement, $\alpha=0.88$; Beneficial, $\alpha=0.85$; External factors, $\alpha=0.78$; and Irrelevance, $\alpha=0.80$. This inventory identifies adaptive and maladaptive responses to assessment that have been shown to influence student achievement in accordance with self-regulation theory (Brown 2011).

The second inventory was the student approaches to learning (SAL) which is a 10 factor, 40-item instrument used in the OECD PISA studies across cultures and languages in 25 countries (Artelt et al. 2003).The 10 factors aggregate in a hierarchical model consisting of the three multidimensional 2nd-order factors: General $(\alpha=0.90)$ has three first-order factors: academic self-concept, selfefficacy, and control expectation; Motivation $(\alpha=0.92)$ has four first-order factors: competitive learning, cooperation learning, instrumental motivation and effort, and perseverance. Learning $(\alpha=0.92)$ has three first-order factors: control strategy, memorization, and elaboration. It has been shown that these factors are invariant and systematically contribute to increased academic achievement.
The third inventory for student evaluation of teaching (SET) experiences was adopted from the secondary school version of Peterson et al. (2000), which has 13 items distributed over three scales: Pupils learn (teacher tells, shows how to do, explains), Warm climate (teacher cares and respects), and Clarity (pupil knows what to do). Despite this, the authors provided alpha estimate of reliability only for the total scale (Cronbach alpha $=0.92$ ).

\section{Academic performance}

Students' NCEA results were obtained from the school records with the permission of each participating student. This section describes first the measures of academic performance and then the self-rated beliefs inventories.

New Zealand certificate of educational assessment (NCEA)

The NCEA is a standards-based assessment system that measures students' academic performance on units (a.k.a., standards) of work against qualitatively determined levels (a.k.a., standards) of achievement or competence. National qualifications are awarded by attaining credits based on the quality of performance on two major classes of assessment standards (i.e., unit standards or achievement standards). Achievement standards are normally associated with traditional school subjects and students; performance is classified as 'achieved', 'achieved with merit', or 'achieved with excellence'. Unit standards are normally associated with vocationally oriented subjects; performance is graded as either 'achieved' (pass), or 'not achieved' (fail). Depending on the amount of work involved in each standard, it is worth a certain number of credits (usually between 2 and 4) and when students successfully completed a standard, the associated credits are counted towards the students' NCEA qualification. While NCEA certificates can be obtained through completing both Unit and Achievement standards, a recent investigation (Madjar et al. 2009) made clear the potentially negative effect of students focusing on unit standards:

Students who choose or are directed into subjects made up predominantly or solely of unit standards or the applied versions of core subjects (such as mathematics and science) early in their NCEA career are likely to find it difficult or impossible to meet the prerequisite requirements for university study in these and related subjects (p. 5).

Standards are organized into 'levels' of increasing difficulty starting from Level 1 to Level 3. Some standards are assessed internally, by the teachers, and some are assessed 
externally in end-of-year exams. Qualifications are gained by building up credits, awarded for each standard achieved. To be awarded a NCEA Level 1 certificate, students must gain 80 credits from Level 1 or higher. Eight credits each must be obtained from both numeracy (Mathematics) and literacy (English) standards. NCEA Level 2 certification requires a minimum of 60 credits at Level 2 or above and twenty credits at any other level. Credits may be used for more than one certification, so some of the students' credits can be counted towards NCEA Level 2 which has no specific numeracy or literacy requirements. For NCEA Level 3 certification, students need to achieve 80 credits, of which 60 must be at Level 3 or above and 20 at Level 2 or above. Normally, Level 1 is assessed at Year 11, Level 2 at Year 12, and Level 3 at Year 13. However, it is common to find students studying at a mixture of levels depending on their ability in the various subject areas.

Internal and external assessment modes are quite different in application. For example, if internal GPA grades are based on unit standards rather than achievement standards, the maximum grade available is 'Achieved' rather than 'Excellence'. Further, many schools permit multiple submissions for internal assessments, and these are often completed in class with considerable guidance and support, in contrast to external assessments which are individual, invigilated, timed, and on-demand examinations. Thus, it makes sense to evaluate the impact of beliefs separately rather than simply relying on the models related to total score. This is especially so if there are clear differences in the number of students doing the internal assessment standards compared to those students doing the external assessment standards.

School records identified all the subjects and levels for which students had gained at least a mark of achieved (Table 2). A total of 21 different subjects at Level 1 and 20 at Level 2 could be identified, indicating the students had taken a wide range of courses. Interestingly, twice as many Level 1 courses were identified as Level 2 despite equal numbers of Year 12 and 13 taking part in the study. This suggests that many of the Tongan students were not keeping pace with the expectation that they would complete a fullcourse load at Level 2 in Year 12. This is consistent with a relatively low level of academic achievement since the Tongan students remained at school but were not making expected progress (Madjar et al. 2009).

There were only two subjects (i.e., English and mathematics) in which there were more than 100 enrolments and only at Level 1 . Because of the small sample sizes per subject, it was not possible to analyse all subjects. Thus, it was decided to use only English and Mathematics Level 1 results. These two subjects are compulsory in NCEA Level 1 , and therefore, most participants had results for these two subject areas. In Mathematics Level 1, 38 standards were
Table 2 Number of students by subjects, levels, and standards for Mathematics/English L1 only

\begin{tabular}{llr}
\hline Subjects/standards & Level 1 & Level 2 \\
\hline Mathematics (unit/achievement) & $149(30 / 8)$ & 52 \\
English (unit/achievement) & $108(27 / 5)$ & 75 \\
Science & 54 & 7 \\
Physical education & 40 & 20 \\
Biology & 34 & 14 \\
Chemistry & 30 & 14 \\
Health & 26 & 5 \\
Geography & 24 & 11 \\
History & 23 & 9 \\
Physics & 20 & 12 \\
Information management & 19 & 0 \\
Visual arts & 17 & 7 \\
Generic & 14 & 13 \\
Social science studies & 13 & 7 \\
Accounting & 11 & 8 \\
Economics & 9 & 5 \\
Dance & 8 & 16 \\
Computing & 7 & 18 \\
Drama & 6 & 8 \\
Music & 6 & 5 \\
Hospitality & 3 & 73 \\
Total & 621 & \\
\hline
\end{tabular}

attempted by participants, 30 of which were unit standards. In English Level 1, 32 standards were attempted of which 27 were unit standards.

\section{GPA scores}

Since students completed so many different standards, each worth different credit points, and across both traditional and vocational approaches to the subject, it was necessary to create a common scale for determining, not just the quantity, but also the quality of academic performance. This common metric of academic performance was created by converting performance within a subject into a grade point average (GPA). The procedure for calculating GPA was adopted from Shulruf et al. (2006) who found that the GPA procedure on NCEA was very effective in predicting first year students' GPA at university. This involved finding out for all the standards at Level 1 , what grade the student got for each standard and the number of credits the unit or standard was worth. The grades were multiplied by a weighting factor (i.e., Achieved $=2$, both for US and AS, Merit $=3$, Excellence $=4$ ), and the sum was divided by the total number of credits obtained by the student. Thus, each student would have a GPA score between 0.00 and 4.00 regardless of the number of credits earned. The 
Table 3 NCEA Level 1 GPA statistics by subject and assessment mode

\begin{tabular}{lccc}
\hline Subject & \multicolumn{2}{l}{ Statistics } & SD \\
\cline { 2 - 4 } & $N$ & $M$ & \\
\hline English & & & 0.82 \\
Internal & 97 & 1.76 & 1.47 \\
External & 50 & 1.48 & 0.86 \\
Total & 108 & 1.72 & \\
Mathematics & & & 0.19 \\
Internal & 148 & 0.96 & 0.42 \\
External & 54 & 0.77 & 0.21 \\
Total & 149 & 0.96 & \\
\hline
\end{tabular}

GPA values below 2.00 indicate that not all students scored at least 'achieved' in all standards attempted

GPA scores, calculated in this way, recognize the quality of achievements and reward students who have achieved standards with merit and excellence, which cannot be done just with the number of credits earned.

For each student, English and Mathematics GPA scores were created for the internally assessed component (GPAInt), the external examination (GPAExt), and the total subject GPA (GPATot) (Table 3). By far, the Tongan students attempted a much higher proportion of internal standards than externals (ratio is 2:1 in English, 3:1 in Mathematics).Unfortunately, but consistent with national statistics, the mean GPA score was very low, though somewhat closer to 'Achieved' in English than in Mathematics. There was considerably more variability in English achievement than mathematics (the SD was nearly 4 times bigger in English than mathematics). This suggests that the Tongans as a whole did poorly in mathematics, acceptably for the most part in English.

\section{Self-report inventories}

A study of Tongan secondary students 'Otunuku (2011) using the three inventories had established the structural characteristics of Tongan SCoA, learning, and teaching.

\section{Student conceptions of assessment}

The Tongan Students' Conceptions of Assessment (SCoA) were hierarchically arranged consisting of seven first-order conceptions (i.e., teacher improves students, selfimprovement, personal enjoyment, class enjoyment, school accountability, student future, and irrelevant). Three second-order factors were found (i.e., improvement, beneficial, and external factors) onto which six first-order factors (excluding irrelevant) were loaded. These three secondorder factors were inter-correlated with each other and the first-order irrelevance factor ('Otunuku 2011). In accordance with Marsh and Hau's (1999) recommendation, the four main factors of the SCoA were used since this produced more items per factor (i.e., improvement had 11 items; beneficial had 8 items; external had 6 items; and irrelevant had 8 items).

\section{Student approaches to learning}

The Tongan responses to the SAL replicated the 10 factors under three main SAL factors (i.e., general, motivation, and learning) ('Otunuku 2011) in accordance with the model put forward by Marsh et al. (2006). The general dimension contains scales are related to control expectation, selfefficacy, and academic self-concept. Motivation contains scales related to competitive learning, cooperative learning, instrumental motivation, and effort and perseverance. Learning contains scales related to control strategy, memorization, and elaboration. However, because of small sample size, it was decided to aggregate responses into the three main approaches in subsequent analyses. The advantage of this was that it increased the number of items contributing to the three factors (i.e., general had 9 items; motivation had 12 items; and learning had 13 items).

\section{Student evaluation of teaching}

Tongan SET found two distinct, yet, strongly inter-correlated factors (individual and collective). The individual factor involved having a personal understanding of how classroom activities relate to learning: a positive evaluation of the school, classroom, and rate of learning. In contrast, the collective factor involved a much stronger sense of collective classroom identity involving content being taught; time to finish work; teacher relationship with the class; peer relationships in the class; and behaviour in class. The estimate of reliability for the two factors was good: Collective, $\alpha=0.79$; and Individual, $\alpha=0.86$. The inter-correlation between the two factors was 0.68 , suggesting reasonably strong connection ('Otunuku 2011). As per Marsh and Hau's (1999) recommendations, these two factors had six items each.

Based on previous studies with these beliefs, it was expected that students' academic performance would be positively predicted by (1) the SCoA improvement factor, (2) all three SAL factors, and (3) both SET factors. It was expected that the remaining SCoA factors (i.e., external, affect, and irrelevant) would have a negative relationship to performance.

Data analyses

To answer Research Question 1 about the structure of student beliefs, CFA of each inventory separately using all 
189 participants was carried out. Since the study used preexisting instruments that had been developed for each construct (assessment, teaching, and learning), models based on those studies were checked to see if the quality of measurement for each construct was adequate. Then, following the conventional 2-step procedure recommended by Anderson and Gerbing (1988), SEM was used to examine the inter-relationships of the various structures. To answer Research Questions 2 and 3, the items making up each factor were parcelled into nine scores (CoA: improve, external, affect, irrelevance; SAL: general, motivation, learning; SET: collective and individual). This approach improves the ratio of cases to items and was necessary given the low $N$ in some analyses.

To answer Research Question 2, a simplified model of three inter-correlated conceptions (i.e., assessment, teaching, and learning), each made up of its contributing factors as parcelled scores, was created. This approach was taken because it was expected that students' beliefs about these conceptions would overlap, meaning that separate models might produce spurious results. By allowing the three beliefs constructs to be inter-correlated, any multicollinearity among these three construct in predicting student achievement could be properly addressed.

Structural equation modelling was used to identify the effect of the various beliefs upon total score in each subject and upon internal and externally assessed performance (Research Question 3). Hence, a total of six models are reported. Statistically, non-significant pathways were removed leaving models with only statistically significant pathways and acceptable fit characteristics. The quality of a structural equation model is determined by inspection of multiple fit indices, with greater weight given to those known to be resistant to model complexity, sample size, and model misspecification (Fan and Sivo 2007). In line with current practice (Cheung and Rensvold 2002; Fan and Sivo 2007; Marsh et al. 2004; Vandenburg and Lance 2000), our criteria for fit were models with statistically non-significant $\chi^{2}$ per $d f$, gamma hat $>0.90$, and root-meansquare errors of approximation (RMSEA) and standardized root-mean residuals $(\mathrm{SRMR})<0.08$. Models that met these criteria were not rejected.

\section{Results}

Research Question 1: Structure of beliefs

Confirmatory factor analysis (CFA) was used to recover the general factor structure of the three beliefs inventories. Each inventory was analysed separately so as to maximise the number of cases per item.
CFA analysis of this inventory recovered the four general factors proposed by Brown's (2006) SCoA inventory with acceptable fitting statistics $\left(\chi^{2}=1,109.73 ; d f=438\right.$; $\chi^{2} / d f=2.59 ; p=0.13 ; \mathrm{CFI}=0.87$; gamma hat $=0.90$; RMSEA $=0.058 ; \quad 90 \% \quad \mathrm{CI}=0.054-0.063 ; \quad$ SRMR $=$ 0.062). The mean and standard deviation for these factors were as follows: Improvement; $M=4.65, \mathrm{SD}=0.89$, External; $M=4.43, \mathrm{SD}=1.05$, Beneficial; $M=4.15$, $\mathrm{SD}=0.97$, Irrelevance; $M=3.07, \mathrm{SD}=0.97$.

CFA analysis of students' approach to learning recovered three factors as proposed in Marsh et al.'s (2006) report about the SAL inventory, though fit was marginal: $\left(\chi^{2}=1818.97, d f=736 ; \chi^{2} / d f=2.47 ; p=0.12 ; \mathrm{CFI}=\right.$ $0.88 ;$ gamma hat $=0.88 ;$ RMSEA $=0.062 ;$ SRMR $=$ 0.064). The mean and standard deviation for these factors were: Motivation; $M=4.70, \quad \mathrm{SD}=0.89$, Learning; $M=4.59, \mathrm{SD}=0.93$, General $M=4.58, \mathrm{SD}=0.95$.

CFA analysis of the SET items found two factors rather than the proposed single factor. This measurement model had good fit characteristics $\left(\chi^{2}=137.03 ; \quad d f=53\right.$; $\chi^{2} / d f=2.59 ; p=0.11 ; \mathrm{CFI}=0.97$; gamma hat $=0.96$; RMSEA $=0.065 ; \quad 90 \% \quad \mathrm{CI}=0.051-0.078 ; \quad \mathrm{SRMR}=$ 0.041). The mean and standard deviation for the two factors were as follows: Individual; $M=4.48, \mathrm{SD}=1.09$, Collective; $M=4.44, \mathrm{SD}=0.97$.

The CFA results, as reported here, support the use of four factors to summarise Tongan student beliefs about assessment, three factors for their approaches to learning, and two factors for their perception of teaching.

Research Question 2: Relationship of beliefs to each other

The inter-correlation of the factors within each belief inventory was examined for the six models (i.e., subject $*$ assessment type) and found to be strong (Table 4). In general, the difference between inter-correlations was statistically not significant between internal and external assessment modes. The only exception was the difference between the Assessment and Learning conceptions correlations which was weaker in the internal coursework mode for English only than in the external examination form of assessment. Hence, we can conclude that the factors are strongly inter-related but sufficiently distinct as to have potentially distinct effects on the achievement.

Research Question 3: Relationship of beliefs to academic performance

The six models all had acceptable to strong fit indices (Table 5) suggesting that the trimmed models need not be rejected. Hence, there are statistically significant predictions 
Table 4 Belief inter-correlations by subject and assessment mode

\begin{tabular}{|c|c|c|c|c|c|c|}
\hline \multirow[t]{3}{*}{ Subject and Scale } & \multicolumn{6}{|c|}{ Inter-correlations } \\
\hline & \multicolumn{2}{|c|}{ Internal } & \multicolumn{2}{|c|}{ External } & \multicolumn{2}{|l|}{ Total } \\
\hline & II & III & II & III & II & III \\
\hline \multicolumn{7}{|l|}{ English } \\
\hline I. Assessment & $0.87 *$ & 0.88 & 0.94 & 0.93 & 0.88 & 0.87 \\
\hline II. Learning & & 0.81 & & 0.90 & & 0.82 \\
\hline III. Teaching & & & & & & \\
\hline \multicolumn{7}{|l|}{ Mathematics } \\
\hline I. Assessment & 0.84 & 0.80 & 0.91 & 0.80 & 0.80 & 0.84 \\
\hline II. Learning & & 0.81 & & 0.83 & & 0.81 \\
\hline III. Teaching & & & & & & \\
\hline
\end{tabular}

* Difference in values between internal and external condition has $p<0.05$

from student beliefs to academic performance on the NCEA Level 1.

The statistically significant predictors of achievement and the amount of variance accounted for in each of the six models are reported in Table 6. Contrary to expectations, there were few beliefs that predicted achievement, consistent with the strong inter-correlations among beliefs. In terms of practical significance, the amount of variance explained for the two internal assessments was trivial $\left(f^{2}<0.07\right.$, Cohen 1992), whereas the beliefs had a moderate effect on the end-of-year external examinations $\left(f^{2}=0.20\right.$ in Mathematics, $f^{2}=0.25$ in English). The beliefs that predicted achievement were quite different between subjects (i.e., assessment conceptions having no effect on English and teaching conceptions having no effect on mathematics). The results indicated that the effect of beliefs on achievement are state-like (i.e., contingent on learning domain and mode of assessment), rather than traitlike (i.e., persistent relationships independent of context).

Furthermore, the different relationship of beliefs to achievement according to subject is consistent with previous findings (Bong et al. 2012; Wigfield 1984). Wigfield (1984) found that student beliefs about mathematics were less positive at each successive grade level, whereas interest in English increased at higher grade levels. Similarly, Bong et al. (2012) found that relationships between students' self-constructs and achievement tended to be stronger in mathematics than in Language Arts.

\section{Assessment conceptions effects}

These conceptions had effects only on the mathematics performance. The negative effect from SCoA Irrelevant was expected and consistent with previous studies and selfregulation theory. In contrast, the positive effect of the social affective benefit assessment conception was surprising, since two previous studies with New Zealand high school students had shown negative or neutral effects of this belief on performance. Among Tongan students, those who endorsed more strongly the conception that assessment improved class morale and cooperation did better on the external mathematics examination. This implies that this small group of Tongan students prepared for NCEA Level 1 external mathematic examination in a collegial, group-fashion, an approach that is consistent with common understanding of collectivist traits in Tongan society (Helu 1999). Hence, in the context of classroom environments for the NCEA, there appears to be a positive effect for Tongan students from believing in the positive social effects of assessment. It remains to be seen if this interpretation is consistent with students' actual study and learning behaviours prior to examinations. Nonetheless, it would seem there is a strong cultural effect in how assessment is understood; in that, Tongan students had different relations than did New Zealand students as a whole. This cultural influence on assessment beliefs has been reported previously with Maori students having different relations from their conceptions of assessment to achievement than all other New Zealand students (Hirschfeld and Brown 2009).

Table 5 Structural equation model fit indices by subject and assessment mode

\begin{tabular}{|c|c|c|c|c|c|c|c|c|c|}
\hline \multirow[t]{2}{*}{ Subject and assessment } & \multicolumn{9}{|c|}{ Fit indices } \\
\hline & $\chi^{2}$ & $d f$ & $\chi^{2} / d f$ & $p$ & CFI & Gamma hat & RMSEA & RMSEA $90 \%$ CI & SRMR \\
\hline \multicolumn{10}{|l|}{ English } \\
\hline Internal & 53.80 & 32 & 1.68 & 0.19 & 0.96 & 0.95 & 0.084 & $0.042-0.122$ & 0.055 \\
\hline External & 51.92 & 31 & 1.67 & 0.20 & 0.95 & 0.91 & 0.117 & $0.057-0.172$ & 0.048 \\
\hline Total & 48.83 & 32 & 1.53 & 0.22 & 0.98 & 0.97 & 0.070 & $0.023-0.108$ & 0.046 \\
\hline \multicolumn{10}{|l|}{ Mathematics } \\
\hline Internal & 43.67 & 32 & 1.37 & 0.24 & 0.99 & 0.98 & 0.050 & $0.000-0.084$ & 0.039 \\
\hline External & 43.38 & 31 & 1.40 & 0.24 & 0.97 & 0.95 & 0.087 & $0.000-0.144$ & 0.055 \\
\hline Total & 45.09 & 32 & 1.41 & 0.24 & 0.99 & 0.98 & 0.053 & $0.000-0.086$ & 0.037 \\
\hline
\end{tabular}


Table 6 Belief effects on NCEA L1 performance by subject and assessment method

\begin{tabular}{|c|c|c|c|c|c|c|c|c|c|c|}
\hline \multirow{3}{*}{$\begin{array}{l}\text { NCEA Level } 1 \text { subject } \\
\text { and assessment }\end{array}$} & \multicolumn{10}{|c|}{ Student beliefs } \\
\hline & \multicolumn{4}{|c|}{ Conceptions of assessment } & \multicolumn{3}{|c|}{ Approaches to learning } & \multicolumn{2}{|c|}{ Conceptions of teaching } & \multirow{2}{*}{$\begin{array}{l}\text { Variance explained } \\
\text { (SMC) }\end{array}$} \\
\hline & Ext & $\operatorname{Imp}$ & Aff & Irr & Gen & Mot & Lrn & Ind & Col & \\
\hline \multicolumn{11}{|l|}{ English } \\
\hline Internal & & & & & & & & 0.18 & & 0.03 \\
\hline External & & & & & -0.51 & & 0.75 & & & 0.20 \\
\hline Total & & & & & & & & 0.36 & & 0.13 \\
\hline \multicolumn{11}{|l|}{ Mathematics } \\
\hline Internal & & & & -0.24 & & & & & & 0.06 \\
\hline External & & & 0.48 & & & -0.52 & & & & 0.17 \\
\hline Total & & & 0.18 & & & & & & & 0.03 \\
\hline
\end{tabular}

Ext external attributions, Imp improvement, Aff affective/social benefit, Irr irrelevant, Gen general, Mot motivation, Lrn learning, Ind individual, $\mathrm{Col}$ collective, SMC squared multiple correlations; values are standardised beta-regression weights

\section{Learning conceptions effects}

The learning approaches had effects only on external examination assessments. The negative effect from SAL motivation (i.e., cooperative learning, competitive learning, instrumental motivation, effort, and perseverance) is understandable given that these four factors had negative to very small associations (ranging from -0.01 to 0.11 ) with mathematics achievement in the PISA studies (Marsh et al. 2006). In English, strong endorsement of learning approaches, as previous studies have shown, was associated with higher achievement. The negative effect of SAL General was surprising, given that the three contributing factors had positive associations with reading achievement (ranging from 0.18 to 0.22 ) in the PISA studies (Marsh et al. 2006). It is possible to speculate that the Tongan students' beliefs about themselves were negatively impacted by a stereotype effect (Steele and Aronson 1995) (i.e., Tongan students do poorly in mathematics). Alternately, since there is no possibility for cooperation during a one-off examination, the Tongan students may have been additionally nervous and unconfident, producing lower self-efficacy and control expectations.

\section{Teaching conceptions effects}

The teaching evaluations had an effect only on the internally assessed English performance. The positive effect of the individual evaluation (i.e., know why we learn what in class, understand enough to finish tasks, my school has good teachers, rules in class help me to learn, school has enough supplies, class is not too slow or too fast to learn well) may be a reflection of students' experiences with how internally assessed standards, including unit standards, are implemented, especially in English classrooms. This result seems consistent with the New Zealand high school students who believed their teachers challenged them, catered for learning needs, and got them to think about the quality of their work in English had higher scores on a standardised English test (Brown and Yu 2010).

\section{Discussion}

As hypothesised, student beliefs about teaching, learning, and assessment had a meaningful relationship with at least the external examination aspects of performance at NCEA Level 1 in English and Mathematics. The proportion of variance explained for external examinations was mediumsized (i.e., $f^{2}=0.20$ Mathematics; 0.25 English) and consistent with the previous studies using the SCoA (Brown and Hirschfeld 2008; Brown et al. 2009b; Walton 2009). These results suggest that control beliefs exercised in a self-regulating manner lead to greater achievement. There are two major patterns of difference in these data. There are differences in the type of assessment (i.e., internal and external assessment modes), and there are differences between subjects (i.e., English and mathematics).

\section{Effect of assessment mode}

Inspection of the enrolment patterns exhibited in Table 2 showed that a very small number of students took external examinations in each subject and that the effect of beliefs was quite different. This suggests that there is something in how students respond to specific, one-off, high-salience examinations or tests that allow student beliefs to have a greater systematic variation with performance. It may be that the test-like nature of such events triggers adaptive motivational responses or the more individualistic nature 
(i.e., no group work, no help) of the test environment allows individual differences to have a greater influence on performance.

Indeed, the school-based internal assessment practices and students' emphasis on group interaction and access to support may contribute to diminishing the impact of individual beliefs on performance. This may even raise doubts as to the integrity of the internal GPA scores-is the performance really and uniquely that of the individual responding to the questionnaire? Alternately, it could be argued that beliefs about other constructs (e.g., the self or the subject or studying) are more critical in predicting performance on formal assessments.

Hence, this study opens the door to the possibility that studying the impact of student beliefs on assessed performance is valid only insofar as the assessment is test-like. This hypothesis could be tested in a future study using the SCoA survey instrument but with specific instructions as to what type of assessment should be evaluated (e.g., either a one-off examination at the end of the year or in class tests during the year or non-test assessments used in NCEA internal assessment unit standards).

\section{Effect of subject domain}

There was a clear difference between English and mathematics in how students' performance was influenced by their belief systems. Given that the belief constructs were highly inter-correlated, it is possible that the pathways from factors to performance are somewhat spurious. Some credibility could be given to this possibility because largerscale studies find consistent patterns of relations between all the three sets of control beliefs and academic performance. Nonetheless, the current study suggests that the student beliefs are responsive to differences in the material being taught, the processes used to teach it, and the means of assessment in each subject. While we might expect selfrelated competence and control beliefs to generalise, there is clear evidence that domain specific measures are more powerful in predicting performance (Schunk and Zimmerman 2006). Alternatively, it is possible that current results, which look like subject-specific effects, may reflect beliefs that are ethnic-group specific. Hence, this study points towards the need for larger-scale studies that have many more Tongan and other Pasifika students to resolve uncertainties between domain and ethnicity effects.

\section{Understanding effects of student beliefs}

The negative effects of the learning factors (containing academic self-concept, self-efficacy, instrumental motivation, interest, and control expectation) on the external GPA are surprising as this runs contrary to general evidence that SAL General positively predicts achievement (Marsh et al. 2006). However, there is evidence among New Zealand students of Pasifika background that teachers and schools prioritize success on easy school work (Nakid 2003). This would suggest that there is a strong teacher effect, as argued by 'Otunuku and Brown (2007), contributing to Tongan students' misunderstanding of their real academic ability. They argued that students are made to feel good (i.e., have high self-efficacy) at the expense of knowing that they are not doing well academically. This interpretation should be taken very cautiously as it is based on just 50/108 Tongan students and is only found in the external assessment condition. Nevertheless, if borne out in largerscale or experimental studies, this mechanism may contribute significantly to understanding why Tongan students are underperforming.

Contrary to self-regulation theory (Boekaerts and Cascallar 2006; Boekaerts and Corno 2005)and previous empirical work(Brown et al. 2009a), the conceptions that assessment is enjoyable or has a positive social effect were not maladaptive on learning outcomes. There may be a socio-cultural effect at work here, in which Tongan students respond to the challenge of external examinations by collaboratively studying for a challenging task (Thaman 1995). It seems likely that Tongan students, when preparing for examinations, would work together to achieve better results. Several studies in New Zealand about the social contexts for learning found students' learning is advanced through learning with others and in a responsive environment with others-like peers and family (Wearmouth et al. 2006; Bishop and Berryman 2009; Madjar et al. 2009; Curtis et al. 2012).Nonetheless, students of different ethnicities may well experience and respond to assessment in quite different fashions; hence, it is plausible that awareness of group cohesion and collaborative study action in the face of assessment may lead to greater performance for students of Tongan background. If this hypothesis is borne out, it would give a clear mechanism by which to take advantage of strong group orientations where they exist among Tongan students-use the groups to prepare for examinations, rather than just as a classroom pedagogical activity. This would probably be a culturally responsive practice that leads to higher academic performance outcomes, but one which may be resisted by teachers and students themselves.

In English only, the teaching conception 'individual' had a statistically important path to performance. This goes against the stereotype of Pasifika students being very group-oriented (Pasikale and Yaw 1998). A closer look at the standards offered in English Level 1 may help explain this. There are nine achievement standards offered at Level 1 , worth a total of 24 credits, half of which are examined 
externally, and half internally assessed by teachers. The 12 internally assessed credits are individually presented (i.e., three are individual presentations and one is producing a piece of creative writing). Further, of the 43 unit standards offered, only one standard (worth two credits) is grouporiented (www.nzqa.govt.nz). Even with the flexible nature of the unit standards, it still comes down to the individual candidate to perform. Hence, it would appear that prioritising group work in classroom settings may undermine the beneficial effects of beliefs around individualised responsibility. It may well be that less group work and more individual work are needed to help students adopt a belief about individual responsibility. In-depth investigations into how students understand and respond to these varying assessment formats would contribute to a deeper understanding of how to design classroom practices for greater learning for Tongan students.

\section{Future research}

First and foremost, this study had a very small sample size (i.e., no more than 190 students), and it is advised that generalizations to the Tongan student population be made cautiously because such a sample size can be highly influenced by individuals in the sample who may not be representative. However, this is the largest survey of its kind with Tongan only samples. The results should be treated as indicative of possible patterns, subject to corroboration with a much larger sample. Furthermore, in order to address the small sample size, the three major constructs of SAL, SCoA, and SET had to be modelled as parcelled items rather than their full factors. This causes considerable loss of precision in the modelling and can only be rectified with larger samples.

Besides, there is considerable co-linearity among the constructs (seen in the strong correlation values between the three conceptions). This means, without larger sample sizes, it is difficult to identify the unique effects of each belief properly and that there is the possibility that the results (i.e., strength and sign of parameters) are attributable to chance characteristics related to the individuals in this small sample. It is also worth noting that the strong inter-correlations imply that future studies into how Tongan students think about learning, assessment, and teaching should examine student thinking about these three constructs simultaneously. Beliefs about teaching cannot be properly understood without access to student thinking about learning and assessment simultaneously. Finally, the authors do not presume that these three educational constructs or their operationalization in the selected scales are necessarily sufficient. There are other relevant constructs (e.g., curriculum, the self, subject matter, the future, intelligence, etc.) that have been shown to have relevance to academic achievement, and there are other instruments for the selected constructs that could not be used in this study. Future research should consider other plausible constructs or instruments. Just as important, the authors acknowledge that the current cross-sectional design only allows the development of hypotheses around the causal relationship of beliefs to achievement. Future research clearly needs longitudinal data so that the possible reciprocal effects between achievement and beliefs can be tracked, and experimental studies in which student beliefs about teaching, learning, and assessment are modified in the hope that changes in accordance with self-regulation theory cause adaptive effects on achievement.

\section{Summary}

This study attempted to understand Tongan senior secondary students' thinking about teaching, learning, and assessment by relating self-reported factor scores to academic performance on the high-stakes NCEA assessments of performance in English and mathematics. The structural models for all internal, external, and total GPA scores across both subjects showed that some beliefs had statistically significant impacts on academic performances, supporting the idea that students' beliefs do matter for learning outcomes. It was noted that different beliefs became statistically significant predictors of performance, depending on the subject and type of assessment. Nonetheless, all three constructs (teaching, learning, and assessment) played some role in at least one subject. A small-to-moderate proportion of variance in NCEA performance could be attributed to student beliefs, suggesting that efforts to help students adopt adaptive beliefs will have beneficial consequences for those students. Furthermore, the results point to future studies and experiments in changing classroom practices that may well lead to higher levels of academic performance. Given the technical difficulties related to doing this type of research with small samples, these results are tentative.

Open Access This article is distributed under the terms of the Creative Commons Attribution License which permits any use, distribution, and reproduction in any medium, provided the original author(s) and the source are credited.

\section{References}

Ajzen, I. (1991). The theory of planned behavior. Organizational Behavior and Human Decision Processes, 50, 179-211.

Ajzen, I. (2005). Attitudes, personality and behavior (2nd ed.). New York: Open University Press. 
Akey, T. M. (2006). School context, student attitudes and behaviour and academic achievement: An exploratory analysis. www.mdrc.org.

Anderson, J. C., \& Gerbing, D. W. (1988). Structural equation modeling in practice-A review and recommended 2-step approach. Psychological Bulletin, 103(3), 411-423.

Artelt, C., Baumert, J., Julius-McElvany, N., \& Peschar, L. J. (2003). Learners for life: Student approaches to learning-Results from PISA 2000. Paris: OECD.

Bishop, R., \& Berryman, M. (2006). Culture speaks: Cultural relationships \& classroom learning. Wellington, New Zealand: Huia.

Bishop, R., \& Berryman, M. (2009). The Te Kotahitanga effective teaching profile. SET: Research Information for Teachers, no. 2, 27 -33, NZCER Press.

Boekaerts, M., \& Cascallar, E. (2006). How far have we moved towards the integration of theory and practice in self-regulation? Education Psychology Review, 18(3), 199-210.

Boekaerts, M., \& Corno, L. (2005). Self-regulation in the classroom: A perspective on assessment and intervention. Applied Psychology: An international review, 54(2), 199-231.

Bong, M., Cho, C., Ahn, H. S., \& Kim, H. J. (2012). Comparison of self-beliefs for predicting student motivation and achievement. The Journal of Educational Research, 105(5), 336-352.

Boomsma, A., \& Hoogland, J. J. (2001). The robustness of LISREL modeling revisited. In R. Cudeck, S. Du Toit, \& D. Sorbom (Eds.), Structural equation modeling: Present and future (pp. 139-168). Lincolnwood, IL: Scientific Software International.

Brown, G. T. L. (2006). Teachers' conceptions of assessment: Validation of an abridged instrument. Psychological Reports, 99(1), 166-170. doi:10.2466/pro.99.1.166-170.

Brown, G. T. L. (2011). Self-regulation of assessment beliefs and attitudes: A review of the Students' Conceptions of Assessment inventory. Educational Psychology, 31(6), 731-748.

Brown, G. T. L., \& Hirschfeld, G. H. F. (2008). Students' conceptions of assessment: Links to outcomes. Assessment in Education: Principles, Policy and Practice, 15(1), 3-17.

Brown, G. T. L., Irving, S. E., \& Peterson, E. R. (2009, August). The more I enjoy it the less I achieve: The negative impact of socioemotional purposes of assessment and feedback on academic performance. Paper presented at EARLI 2009 biennial conference, Amsterdam, NL.

Brown, G. T. L., Peterson, E. R., \& Irving, S. E. (2009b). Selfregulatory beliefs about assessment predict mathematics achievement. In D. M. McInerney, G. T. L. Brown, \& G. A. D. Liem (Eds.), Student perspectives on assessment: What students can tell us about assessment for learning (pp. 159-186). Charlotte, NC: Information Age Publishing.

Brown, G. T. L., \& Yu, K. L. (2010, July).Student evaluation of teaching, learning attitudes and academic performance: Perceptions from New Zealand high school students. Poster presented at the International Test Commission biannual conference, Hong Kong.

Cheung, G. W., \& Rensvold, R. B. (2002). Evaluating goodness-of-fit indexes for testing measurement invariance. Structural Equation Modeling, 9(2), 233-255.

Cohen, J. (1992). A power primer. Psychological Bulletin, 112(1), $155-159$.

Curtis, E., Wikaire, E., Lualua-Aati, T., Kool, B., Nepia, W., Ruka, M., et al. (2012). TatouTatou: Improving Maori student success. Paper presented at Tuiate Ako, Wellington, New Zealand.

Fan, X., \& Sivo, S. A. (2007). Sensitivity of fit indices to model specification and model type. Multivariate Behavioral Research, 42(3), 509-529.

Helu, I. F. (1999). Critical essays: Cultural perspectives from the South Seas. Canberra: Australia National University Printing Services.
Hirschfeld, G. H. F., \& Brown, G. T. L. (2009). Students' conceptions of assessment: Factorial and structural invariance of the SCoA across sex, age, and ethnicity. European Journal of Psychological Assessment, 25(1), 30-38.

Jones, A. (1991). At school I've got a chance. Culture/privilege: Pacific Islands and Pakehaddgirls at school. Palmerston North, NZ: Dunmore Press.

Little, R. J. A., \& Rubin, D. B. (2002). Statistical analysis with missing data (2nd ed.). New York: John Wiley.

Madjar, I., Mckinley, E., Jensen, S., \& Merwe, A. (2009). Towards University: Navigating NCEA course choices in low-mid decile schools. Unpublished report, Starpath Project, University of Auckland.

Marsh, H. W., \& Hau, K. T. (1999). Confirmatory factor analysis: Strategies for small sample sizes. In R. H. Hoyle (Ed.), Statistical strategies for small sample research (pp. 251-284). London: SAGE Publications.

Marsh, H. W., Hau, K.-T., Artelt, C., Baumert, J., \& Peschar, J. L. (2006). OECD's brief self-report measure of educational psychology's most useful affective constructs: Cross-cultural, psychometric comparisons across 25 countries. International Journal of Testing, 6(4), 311-360.

Marsh, H., Hau, K. T., \& Wen, Z. (2004). Insearch of golden rules: Comment on hypothesis-testing approaches to setting cutoff values for fit indexes and dangers of overgeneralizing $\mathrm{Hu}$ and Bentler's findings. Structural Equation Modeling, 11(3), 320-360.

Ministry of Education [MOE]. (2008). New Zealand schools: Nga kura o Aotearoa (2007). Wellington, New Zealand: Ministry of Education.

Nakid, C. (2003). Comparing Pasifika students' perceptions of their schooling with the perceptions of non-Pasifika teachers using the 'mediated dialogue' as a research methodology. New Zealand Journal of Educational Studies, 38(2), 207-226.

'Otunuku, M. (2011). Tongan conceptions of schooling in New Zealand: Possible insights and solutions to underachievement. Unpublished doctoral thesis, University of Auckland, Auckland, New Zealand.

'Otunuku, M., \& Brown, G. T. L. (2007). Tongan students' attitudes towards their subjects in New Zealand relative to their academic achievement. Asia Pacific Education Review, 8(1), 117-128.

Pasikale, A., \& Yaw, W. (1998). Weaving the way. Wellington: Pacific Island Education Unit.

Peterson, E. R., Brown, G. T. L., \& Irving, S. E. (2010). Secondary school students' conceptions of learning and their relationship to achievement. Learning and Individual Differences, 20(3), 167-176. doi:10.1016/j.lindif.2009.12.004.

Peterson, K., Wahlquist, C., \& Bone, K. (2000). Student survey for school teacher evaluation. Journal of Personnel Evaluation in Education, 14(2), 135-153.

Randel, B., Stevenson, H. W., \& Witruk, E. (2000). Attitudes, beliefs, and mathematics achievement of German and Japanese high school students. International Journal of Behavioral Development, 24(2), 190-198.

Sarwar, M. (2004). Relationship of study attitude and academic performance of student at secondary level in Punjab. Unpublished $\mathrm{PhD}$ thesis, University of Arid agriculture, Rawalpindi.

Satherley, P. (2006). Student outcome overview 2001-2005: Research findings on student achievement in reading, writing and mathematics in New Zealand schools. Wellinfton, NZ: Ministry of Education, Research Division.

Schunk, D. H., \& Zimmerman, B. J. (2006). Competence and control beliefs: Distinguishing the means and ends. In P. A. Alexander \& P. H. Winne (Eds.), Handbook of educational psychology (2nd ed., pp. 349-367). Mahwah, NJ: LEA.

Shulruf, B., Hattie, J. A., \& Tumen, S. (2006). The predicability of enrolment and first year university results from secondary school 
performance (technical report). Auckland, New Zealand: University of Auckland, Starpath Project.

Statistics New Zealand [SNZ]. (2007). Tongan people in New Zealand: 2006 (publication no. ISBN 9780478-269901). www.stats.govt.nz, from Statistics New Zealand.

Steele, C., \& Aronson, J. (1995). Stereotype thread and the intellectual test performance of African-Americans. Journal of Personality and Social Psychology, 67, 797-811.

Stevenson, H. W., Chen, C., \& Lee, S. Y. (1993). Mathematics achievement of Chinese, Japanese and American Children: Ten years later. Science, 259, 53-58.

Thaman, K. (1995). Concepts of learning, knowledge and wisdom in Tonga and their Relevance to modern education. Prospects, 22(4), 723-733.

Udoukpong, B. E., Emah, I. E., \& Umoren, S. E. (2012). Student attitudes, parental influence and career aspirations in academic achievement in entrepreneurial curriculum. Academic Research International, 2(1), 527-534.

Vandenburg, R. J., \& Lance, C. E. (2000). Toward a further understanding of and improvement in measurement invariance methods and procedures. Organizational Research Method, 5(2), 139-158.

Walton, K. F. (2009). Secondary students' conceptions of assessment mediated by self-motivational attitudes: Effects on academic performance. Unpublished masters thesis, University of Auckland, Auckland, New Zealand.

Wearmouth, J., Glynn, T., \& Berryman, M. (2006).Supporting students with literacy difficulties: A responsive approach.Open University Press, UK.

Wigfield, A. (1984). Relationships between ability perceptions, other achievement related beliefs and school performance. Paper presented at the annual meeting of the American Educational Research Association, New Orleans, LA. 